\title{
INTERPRETAÇÃO DA DINÂMICA FLUVIAL EM UM TRECHO CANALIZADO DO RIBEIRÃO DOS POÇOS E SEUS DESDOBRAMENTOS: UMA CONTRIBUIÇÃO AOS ESTUDOS DA PAISAGEM EM ESCALA DE DETALHE NA CIDADE DE POÇOS DE CALDAS-MG
}

\author{
Thomaz Alvisi de Oliveira ${ }^{(a)}$ \\ (a) Curso de Geografia/Instituto Federal do Sul de Minas Gerais, thomaz.oliveira@ifsuldeminas.edu.br
}

Eixo: Uso e ocupação das terras e legislação ambiental

\begin{abstract}
Resumo
Drenagens condicionadas ao advento da urbanização tem seu equilíbrio rompido e os fluxos de energia e matéria reorganizados, culminando na instalação ou reativação de processos geomorfológicos ao longo do leito e junto às porções marginais. Este estudo é uma a interpretação da dinâmica fluvial de uma drenagem canalizada e retilinizada, em um trecho de 3,8 quilômetros de extensão, inserido no contexto urbano do município de Poços de Caldas-MG. As considerações aqui apresentadas referem-se à resposta sistêmica da drenagem diante das alterações decorrentes da urbanização e aos desdobramentos desse ajuste no que toca aos processos erosivos e deposicionais envolvidos, entendidos aqui como trabalho fluvial visando a retomada do padrão original e consequentemente, de seu perfil de equilíbrio. As reflexões que seguem embasam estudo que vem sendo desenvolvido em âmbito municipal e que atenta para a relação existente entre o crescimento da cidade e o desencadeamento de proceossos geomorfológicos.
\end{abstract}

Palavras chave: Drenagens; Urbanização; Processos geomorfológicos.

\section{Introdução}

O histórico da ocupação urbana de muitas cidades brasileiras é marcado pela intervenção agressiva que se desdobra junto aos ambientes cuja dinâmica está ajustada aos eventos pluviométricos sazonais, que acarretam o aumento das vazões fluviais no período primavera/verão e a diminuição das mesmas no outono/inverno. Esse funcionamento é típico das áreas tropicais úmidas, principalmente onde os efeitos da continentalidade se fazem com mais intensidade.

Quando a superfície topográfica dessas áreas apresenta-se com declividades acentuadas e amplitudes altimétricas significativas, o advento urbano nesses ambientes torna-se elemento complicador, pois potencializa, num primeiro momento, a energia cinética das vertentes e dos canais fluviais quando altera, por exemplo, a rugosidade das superfícies envolvidas por meio da pavimentação e intensifica o transporte nas calhas fluviais quando utiliza-se da retilinização. 
Receptores dos volumes transferidos pela via "topo-fundo de vale", em espaço temporal cada vez mais curto por conta da alteração no tempo concentração da água nas bacias, as drenagens fluviais urbanas respondem dinamicamente. Nesse contexto, alguns canais fluviais outrora "libertos" em planícies abertas, desenvolvem um trabalho voltado à retomada dos seus padrões originais, bem como dos seus perfis de equilíbrio. Subjugam as porções marginais a processos de solapamento e redistribuem o desgaste erosivo no leito pela instalação de pequenas vagas de erosão regressiva, formadas pela presença de carga sedimentar com granulação mais grosseira que é depositada assim que a energia para o transporte se torna insuficiente.

O trabalho que ora se apresenta é resultado de uma investigação processada junto a um trecho retilinizado do ribeirão dos Poços, utilizando-se basicamente de observações de campo e da bibliografia técnica existente. As reflexões que seguem embasaram-se na temática sistêmica e procuram orientar a interpretação da dinâmica fluvial no trecho analisado.

Destacamos que a toponímia apresentada na folha topográfica Poços de Caldas SF-23-V-C-VI-4 será adotada para designação do canal fluvial em questão em detrimento daquela anotada no sítio do Centro Nacional de Monitoramento e Alertas de Desastres Naturais-CEMADEN, onde a grafia informa sobre o rio Lambari.

\section{Pressupostos Teóricos}

O interesse pelo comportamento das drenagens associadas a ambientes urbanos transcende uma ou outra área da ciência, sendo que, aquelas assentadas no âmbito das engenharias e das ciências da terra oferecem melhores análises aos desdobramentos que uma urbanização pode promover junto aos canais de drenagem, quando considerados os processos geomorfológicos envolvidos nessa sistêmica.

Christofoletti (1980) define que a aplicação da teoria dos sistemas ao estudo da dinâmica fluvial pressupõe um estado de estabilidade quando a importação e a exportação de energia e matéria nesses ambientes encontram-se equacionadas, sendo o próprio sistema autorregulador. As alterações nas condições ambientais impõem a necessidade de alteração compensatória no direcionamento ou na intensidade dos fluxos energéticos, culminando em reorganização de todo o sistema.

A respeito da instalação do ambiente urbano junto às áreas de domínio fluvial, Cunha (2003) apresentou algumas considerações, destacando que um dos problemas existentes nesse contexto é a expansão do equipamento urbano sem que haja respeito às condições naturais necessárias para permitir equilíbrio do ciclo hidrológico e do escoamento de superfície, sendo o impacto resultante diretamente proporcional ao 
tamanho e à intensidade dessa intervenção. A relação "intervenção x impacto" destacada pela autora (op. cit) ilustra, de forma inconteste, a condição sistêmica desses ambientes.

Sobre dos fluxos de energia que circulam nos ambientes fluviais, Christofoletti (1980) informa que a transformação da energia potencial de um canal de drenagem em energia cinética acarreta em utilização de parte dessa energia para o trabalho de fricção, responsável pelo desgaste do leito e das margens. Segundo o autor (op. cit), a quantidade de energia cinética disponível em um canal de drenagem é inversamente proporcional à intensidade do trabalho realizado no desgaste e no transporte da matéria. Tal fato esclarece que os fluxos de matéria trabalhados pelos canais fluviais estão diretamente relacionados ao input energético que esses mesmos canais recebem e que o potencial erosivo do canal está diretamente relacionado ao recebimento de uma cota mínima de energia.

Utilizando-se da concepção sistêmica em análise à dinâmica dos espaços em organização, Tricat (1977) definiu três classes para caracterizar a dinâmica ecológica dos meios ambientes, a saber: os meios estáveis, os meios intergrades e os meios instáveis. Esses últimos servem de exemplo para definir a situação caótica em que se encontram os ambientes tomados pela urbanização, onde a relação entre a pedogênese e a morfogênese foi quebrada bruscamente, com intensificação da última em detrimento da primeira. Nos ambientes urbanos, onde a lavagem e a remoção dos materiais dispostos à superfície são intensas, as drenagens fluviais canalizadas ou retilinizadas passam a receber, além de um volume hídrico extra, uma carga sedimentar com granulometria potencialmente mais grosseira. Assim, esses canais, principalmente aqueles de ordens hierárquicas superiores, tem seus leitos e margens atacados por processos erosionais em decorrência do transporte por saltação do material mais grosseiro e pela pressão lateral exercida pelo fluido em escoamento.

O município de Poços de Caldas, região sul do estado de Minas Gerais, encontra-seassentado sobre cotas altimétricas superiores a 950 metros, sendo que, porção considerável localiza-se no interior do Planalto de Poços de Caldas, onde a topografia atinge cotas superiores a 1.500 metros. A denominação "Planalto de Poços de Caldas" foi utilizada por Ellert (1959) para designar o modelado estrutural formado no cretaceo superior, cuja gênese tectonovulcânica deu conta de criar uma superfície "circular" desnivelada altimetricamente das porções circunvizinhas, externas e internas. Os topos mais altos dessa estrutura anelar posicionam-se acima de um ambiente urbano, em parte adensado sobre uma superfície cuja rugosidade é marcada pelas declividades expressivas e pelas amplitudes altimétricas significativas, justapostas entre topos e fundos de vale.

Poços de Caldas tem no seu histórico de ocupação a marca do assentamento urbano sobre vertentes declivosas e fundos de vale. A condição topográfica dos terrenos correlatos à área ocupada pela "urbe" e 
sobre a qual a mesma se expande rapidamente, oferece facilidade para o escoamento pluvial, principalmente quando a superfície passa à condição de impermeável por conta da pavimentação.

Oliveira (2013) investigou o funcionamento multiescalar da paisagem urbana de Poços de Caldas pautando os processos geomorfológicos derivados do escoamento das águas pluviais e fluviais e deu conta de ilustrar o cenário sistêmico que se contextualiza nas porções onde as alterações nos perfis fluviais em ajuste às novas demandas de energia são mais severas.

Em outra comunicação, Oliveira (2013) apresentou apreciações sobre a influência das precipitações e da topografia na dinâmica geomorfológica das superfícies tomadas pela cidade. Nesse trabalho, o autor (op. cit) identificou o trecho do canal ora em análise como potencial à ocorrência de processos de extravasamento do leito em função do aumento do volume hídrico e da carga detrítica.

Mais recentemente Sardinha et. al (2016) apresentaram resultados sobre um estudo voltado à constituição de uma base dados de desastres naturais no município de Poços de Caldas onde o trecho aqui considerado novamente foi reconhecido como potencial à enchentes e alagamentos vinculados aos processos de transbordamento da drenagem principal.

Tendo em vista as informações prestadas por estudos já desenvolvidos no ambiente urbano de Poços de Caldas, atentou-se para a oportunidade de apresentar uma interpretação sobre a dinâmica fluvial de uma drenagem canalizada e retilinizada, em um trecho de 3,8 quilômetros de extensão, inserida no contexto urbano do município em questão. O trecho fluvial analisado é a porção final do ribeirão dos Poços, ajustado entre o início da Avenida João Pinheiro e a ponte sobre seu leito em frente da estação rodoviária do município. É essa drenagem que capta toda a água proveniente de duas subbacias importantes do planalto, a bacia hidrográfica do ribeirão da Ponte Alta e a bacia hidrográfica do córrego da Serra, as duas intensamente urbanizadas.

A Figura 1 ilustra o contexto geral do trecho analisado do ribeirão dos Poços no âmbito urbano do município de Poços de Caldas. 


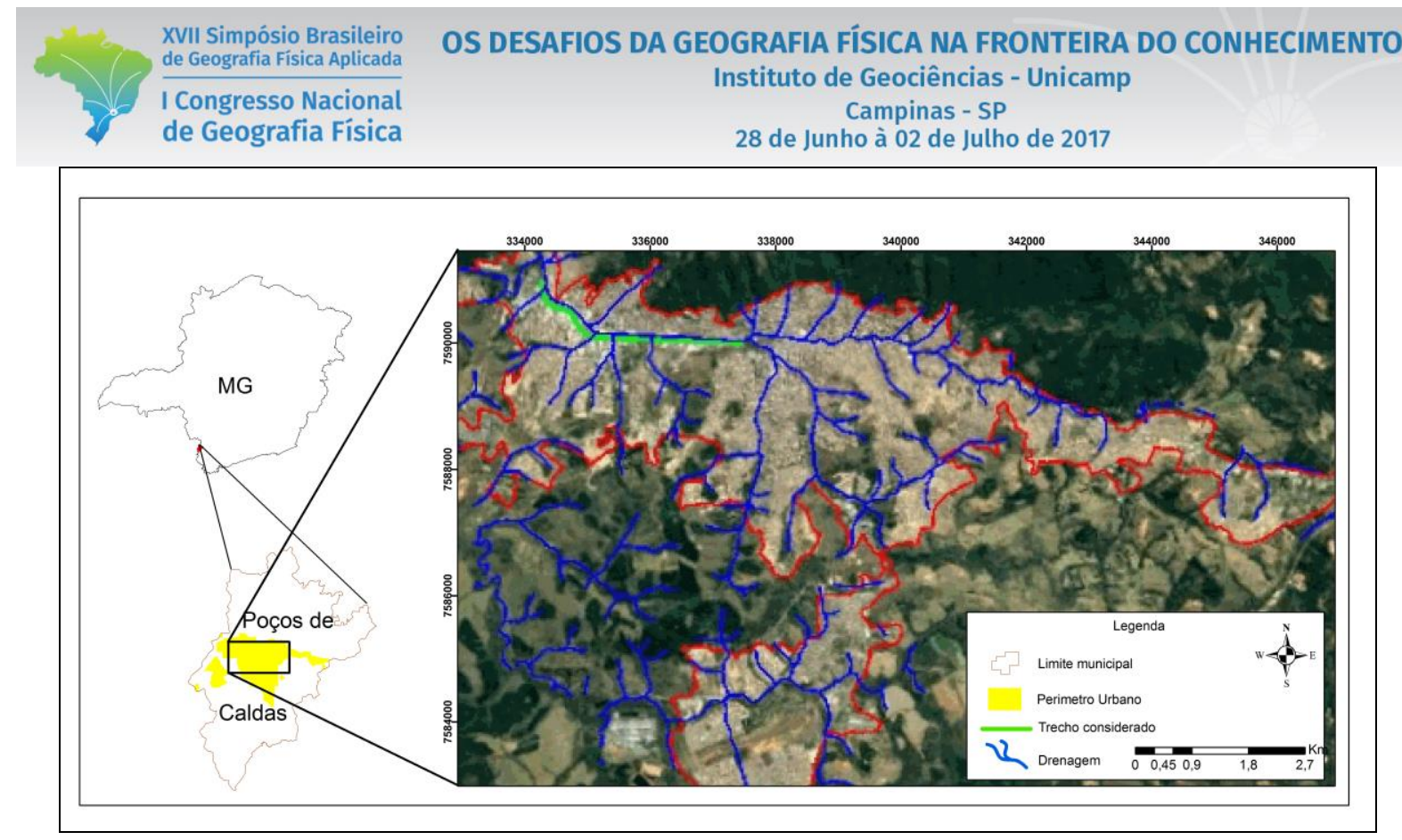

Figura 1 - Contextualização do trecho estudado do ribeirão dos Poços junto à área urbana de Poços de Caldas-MG.

\section{Método de trabalho}

O trabalho teve início com observações em campo que suscitaram interesse em investigações mais pontuais sobre a dinâmica fluvial de um trecho do ribeirão dos Poços. Em sequência, seguiu-se à consulta bibliográfica específica seguida de uma etapa de campo que deu conta do registro fotográfico necessário e de embasar as reflexões cabíveis. Informações pluviométricas e fluviométricas foram fornecidas pelo Centro Nacional de Monitoramento de Desastres Naturais-CEMADEN.

Os materiais utilizados na elaboração do trabalho compuseram-se de uma câmera fotográfica e de uma cena da área, adquirida junto ao aplicativo Google Earth Pro, que foi posteriormente trabalhada no software ArcGIS 10 para a elaboração das informações cartográficas necessárias.

\section{Resultados e discussões}

O ribeirão dos Poços recebe boa parte do volume das águas escoadas na área urbana do município de Poços de Caldas. O monitoramento efetuado por uma estação hidrológica no início do trecho considerado mostra que o canal responde rapidamente aos eventos pluviométricos com o aumento da vazão. (Figuras 2 A e B) 


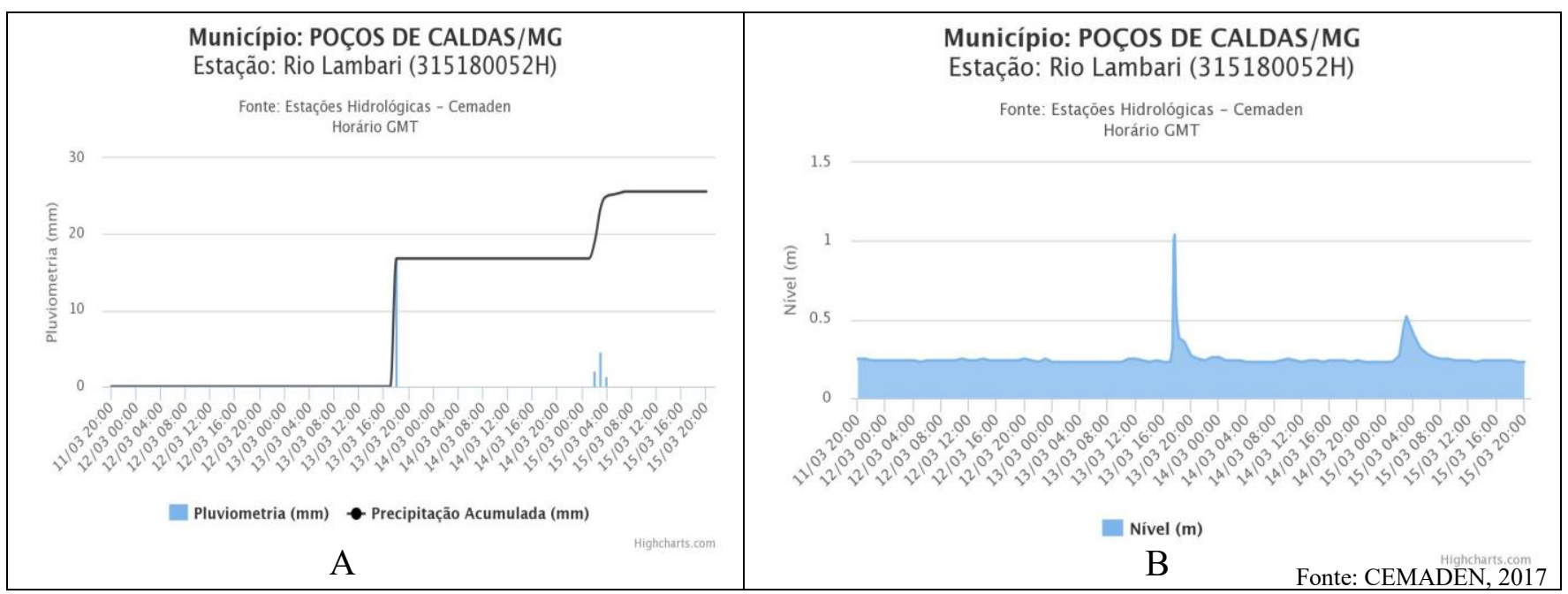

Figuras 2 A e B : Pluviometria (A) e hidrometria da seção do canal (B) monitorada pela CEMADEN

Da mesma forma, a esse aumento repentino da vazão é seguido um rebaixamento rápido do nível da água.

Tal comportamento denuncia que a impermeabilização urbana é provavelmente reponsável pela transferência rápida do volume escoado pelas vertentes ao canal de drenagem. Dadas as características morfométricas das vertentes, a pequena extensão entre topos e fundos de vale e a energia disponível para o arraste, materiais de granulação grosseira são deslocados para dentro do canal. Essa interpretação encontrou apoio nos depósitos locados junto às margens, onde aguardam nova oportunidade de transporte. ( Figura 3 A, B e C)

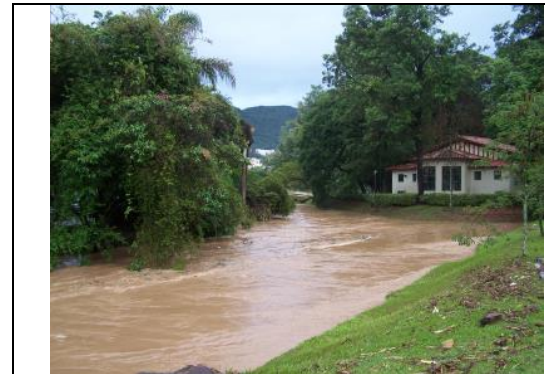

A

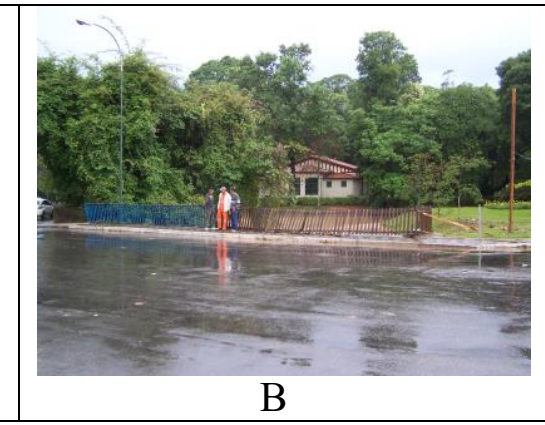

B

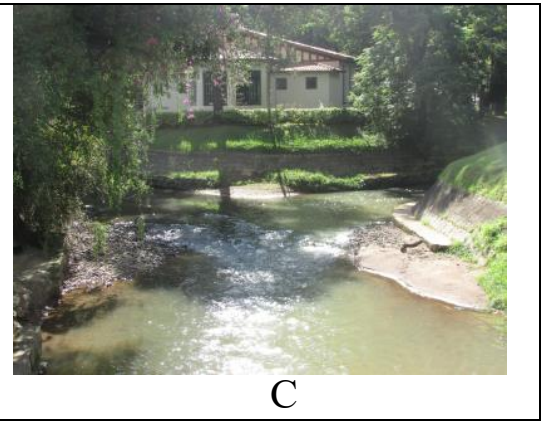

C

Figura 3 A, B e C - Oscilação do nível da água na seção monitorada pela CEMADEN . Quando o volume de água aumenta na calha fluvial (A) a tendência ao transbordo é inevitável (B). Após os picos de subida, a seção se esvazia rapidamente deixando às margens, material disponível para o transporte (C). 


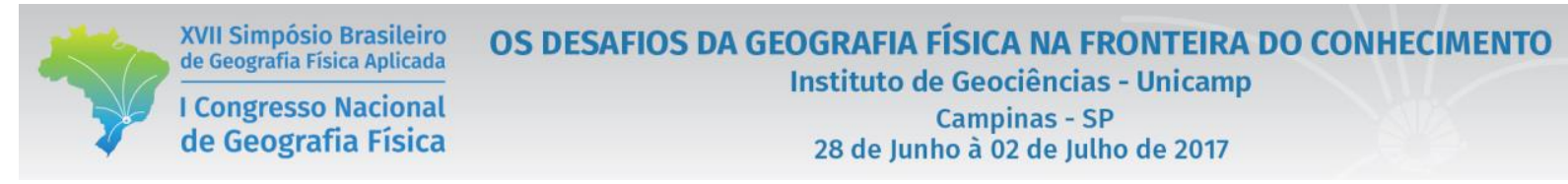

O transporte desses materiais ao longo do canal, quando dos picos de vazão, é feito por saltação e, a depender do volume envolvido e da quantidade de sedimentos, condicionam maior ou menor desgaste do leito e das margens. As fissuras criadas pela pressão lateral da água e pelo atrito do material por ela carreado proporcionam a fragmentação das porções marginais e a escavação nas porções inferiores das seções, induzindo a instalação de processos de solapamento. (Figura 4 A e B)

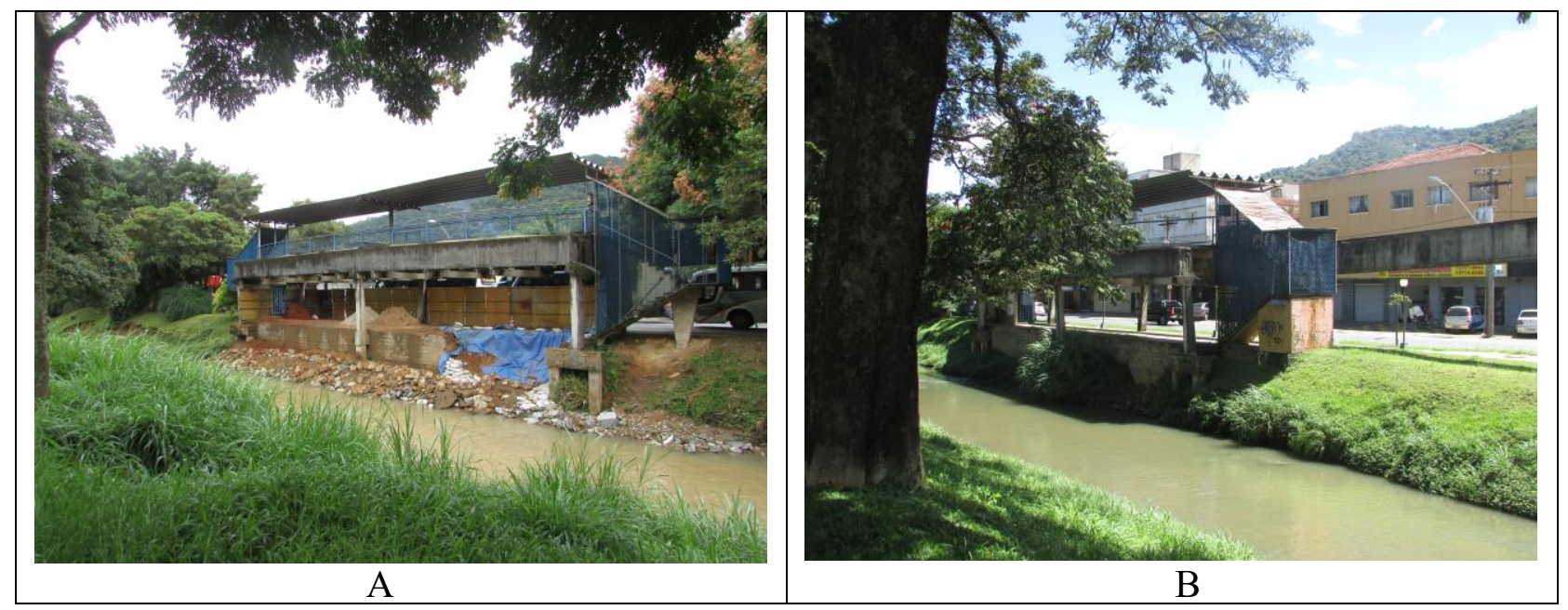

Figura 4 A e B - Margem direita do ribeirão dos Poços atacada por processo de solapamento. $\mathrm{O}$ atrito do material carreado nos momentos de cheias exerce pressão sobre as margens justapostas pelo adensamento urbano (A). Posteriormente às cheias, obras de engenharia dão conta de minimizar os danos até que um próximo evento pluviométrico dê oportunidade para os processos descritos acima entrarem em cena novamente (B).

Na medida em que o canal perde competência para o arraste do material mais grosseiro, o mesmo é abandonado ao longo do leito, configurando pequenos obstáculos ao fluxo hídrico normal. A deposição de material ao longo da calha fluvial torna-se responsável pelo redirecionamento local das correntes, dando início a um processo inicial de meandramento, identificado pela pequena sinuosidade que toma forma no trecho retilinizado do canal. Tal processo revela o trabalho da drenagem na busca do seu padrão natural, ora impedido pelo condicionamento urbano da antiga planície. (Figuras 5 A e B). 

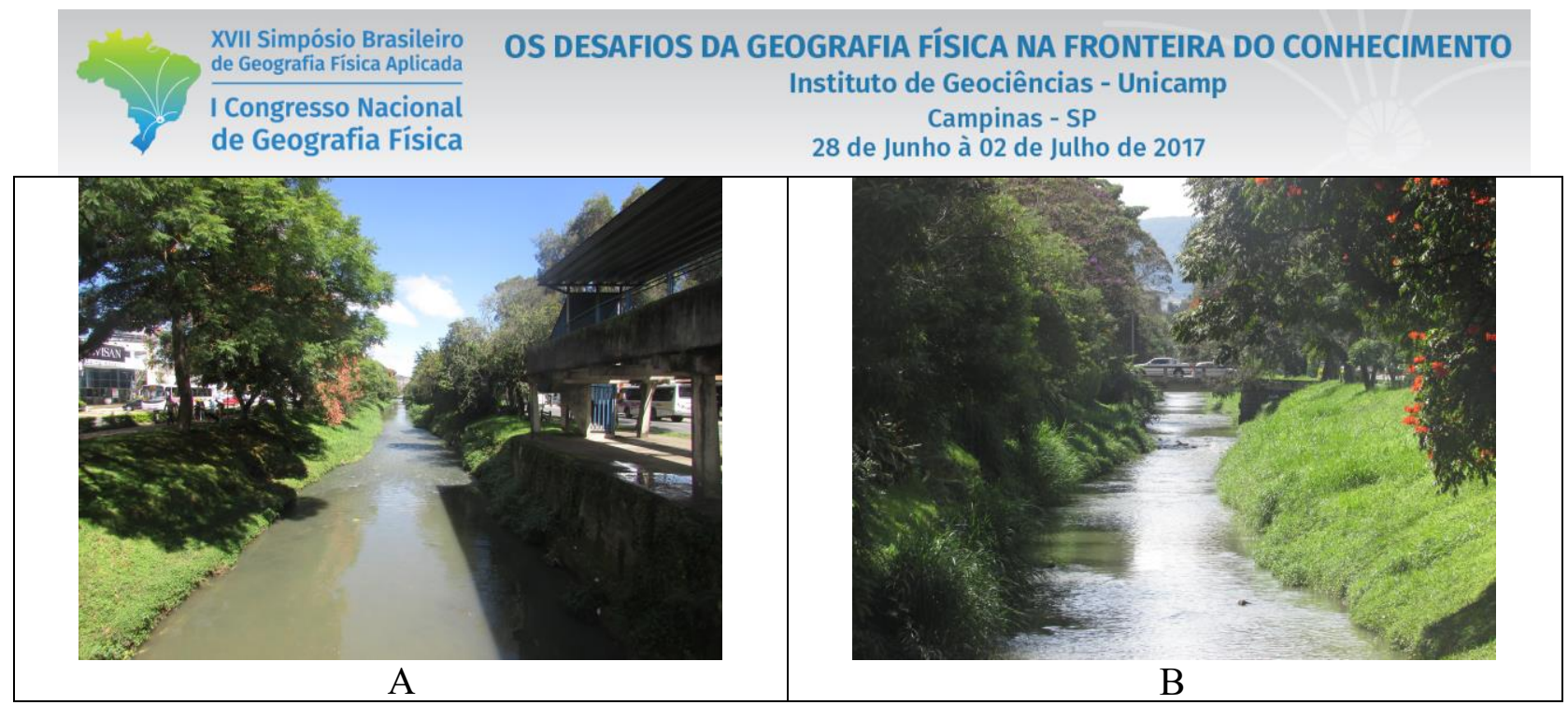

Figura 5 A e B - Em seu trecho retilinizado (A), o ribeirão dos Poços retoma o meandramento (B) ao distribuir a matéria trabalhada no leito, buscando atingir o seu padrão original.

Esse mesmo processo incipiente de meandramento oferece condições ao desgaste das estruturas que canalizam as drenagens tributárias, quando os fluxos são redirecionados às confluências. Ao desgaste produzido pelo fluxo do canal principal, segue o solapamento e a instalação de uma linha de erosão remontante no canal tributário com tendência à rápida evolução, propiciando o desmonte das estruturas urbanas implantadas. (Figura $6 \mathrm{~A}$ e B)

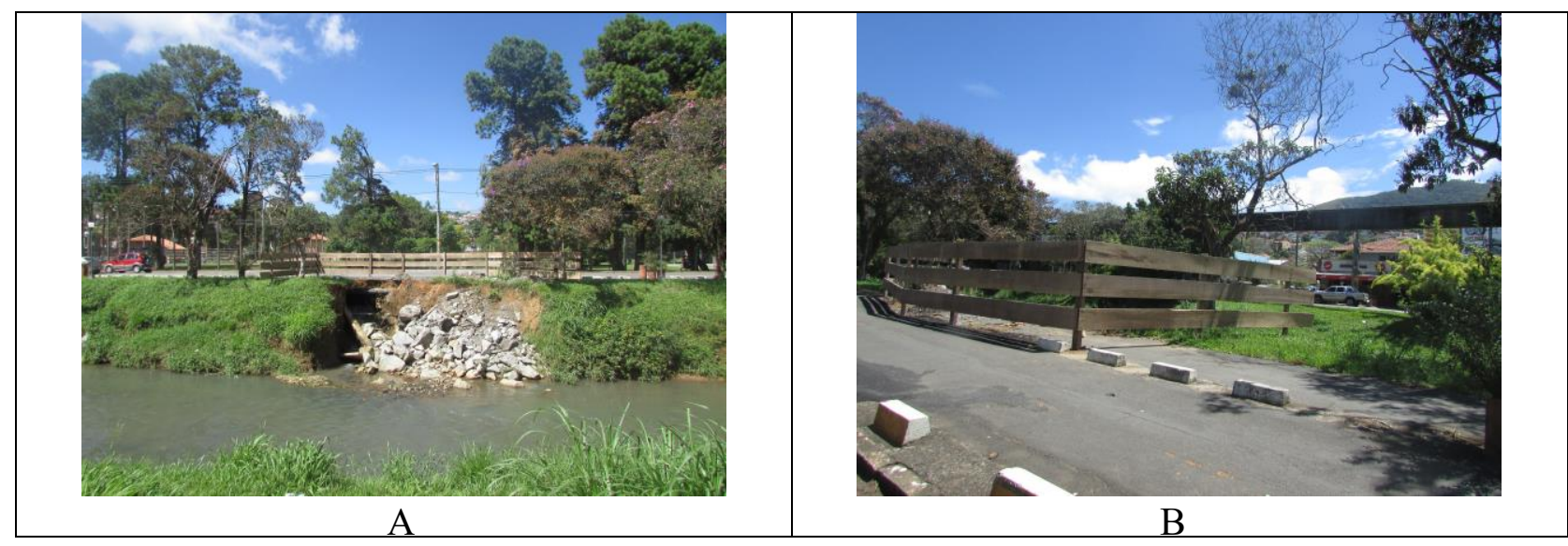

Figura 6 A e B - Confluência canalizada de canal tributário ao ribeirão dos Poços, atingida por processos de solapamento e condicionada à erosão regressiva $(\mathrm{A})$. Nesses termos, os processos em atividade tendem à rápida evolução, com prejuízos aos equipamentos urbanos instalados (B).

É de se considerar que a atuação antropogênica na extensão analisada do ribeirão dos Poços ofertou um novo input de energia a um sistema que, ao recebê-la, se reorganizou para reequilibrar os fluxos matéria antes ajustados às condições anteriores. Os resultados daí advindos culminaram no desencadeamento de processos geomorfológicos ao longo da calha fluvial e porções marginais em resposta às novas condições energéticas que se impuseram. Porém, como o sistema é auto-regulador, ao mesmo tempo que os processos desencadeados funcionam como remodeladores de uma paisagem natural que gradativamente migra para um contexto mais artificializado na medida em que a cidade se expande, denunciam o 
XVII Simpósio Brasileiro

de Geografia Fisica Aplicada

I Congresso Nacional

de Geografia Física
OS DESAFIOS DA GEOGRAFIA FÍSICA NA FRONTEIRA DO CONHECIMENTO

Instituto de Geociências - Unicamp

Campinas - SP

28 de Junho à 02 de Julho de 2017

comportamento do sistema fluvial em questão, que no trecho analisado, procura retomar seu padrão original e com isso seu perfil de equilíbrio.

A Figura 7 expõe de forma pitoresca a condição pretérita do ribeirão dos Poços, quando suas margens ainda oportunizavam a migração livre do canal e os fluxos de matéria estavam ajustados a um input energético muito pouco antropogênico.

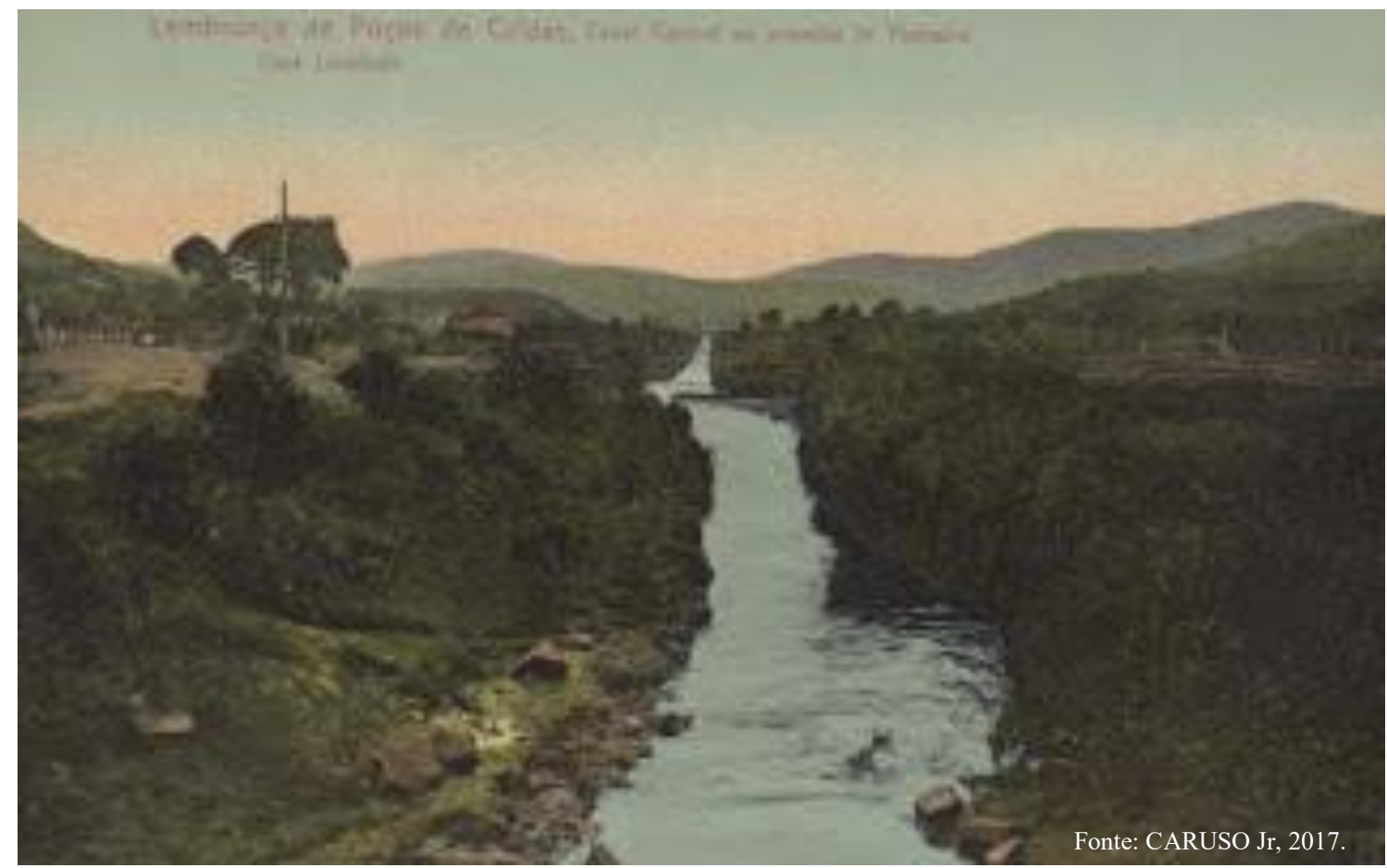

Figura 7 - Paisagem pictórica pretérita representativa do trecho aalisado do Ribeirão dos Poços.

\section{Considerações Finais}

A dinâmica aqui retratada é típica de drenagens outrora meandrantes e que passaram ao padrão retilinizado por conta das adequações da calha fluvial diante das constantes investidas do aparelhamento urbano em um processo de expanção que requisita a todo custo um espaço dominantemente fluvial.

Como já destacado anteriormente as reflexões que são aqui apresentadas seguem em consonância com outras que serão levadas à frente, em trabalho pautado na investigação da expansão da cidade de

Poços de Caldas e sua relação com os processos geomorfológicos que se instalam ou são retomados diante da nova realidade paisagística, condicionada pelo elemento antrópico. 


\section{Bibliografia}

CARUSO JR. R. Memória de Poços de Caldas. Disponível em: http://www.memoriadepocos.com.br/search/label/Mem\%C3\%B3ria\%20Fotogr\%C3\%A1fica. Acesso em 03 de mar. 2017.

CENTRO DE NACIONAL DE ALERTA E MONITORAMENTO DE DESASTRES NATURAIS. Estações Hidrológicas. 15 de mar. 2017.

CHRISTOFOLETTI, A. Geomorfologia. São Paulo; Blucher, 1980.

CUNHA, S. B. Canais fluviais e a questão ambiental. In: CUNHA, S. B; GUERRA, A. J. T. G. (Org.). A questão ambiental: diferentes abordagens. Rio de Janeiro: Bertrand Basil, 2003. Cap. 7.

ELLERT, R. Contribuição à geologia do maciço alcalino de Poços de Caldas. Bol. Fac. Filos. Ciênc. Let. Univ. São Paulo, 237, Geologia 18, p. 1-64, 1959.

OLIVEIRA, T. A. Ótica Geográfica orientada à análise da paisagem urbana de Poços de Caldas (MG): expressão e funcionamento. In: ANDRADE, A. C.; ANDRADE, A. E. N. (Org.). Cidades em Movimento. Jundiaí: Paco Editorial, 2013. Cap-2.

OLIVEIRA, T. A. Implicações sobre a ocupação urbana no município de Poços de Caldas-MG: as precipitações, a topografia e os processos desencadeados. In: XV SIMPÓSIO BRASILEIRO DE GEOGRAFIA FÍSICA APLICADA, 15, 2013, Vitória. Anais...Vitória: UFES, 2013. v. 1, p. 63 - 71.

SARDINHA, D. S. ; PENA, Y. T. L.; TIEZZI, R. O.; ALMEIDA, M. C. J . Base de dados de desastres naturais no município de Poços de Caldas/MG: ferramenta para o planejamento e a gestão territorial. Urbe. Revista Brasileira de Gestão Urbana , v. v9, p. 303-317, 2016.

TRICART, J. Ecodinâmica. Rio de Janeiro: IBGE/Diretoria Técnica/SUPREN, 1977. 